\title{
Prevalence and distribution of paratuberculosis [Johne's disease) in cattle herds in Ireland
}

\author{
Good $\mathrm{M}^{1}$, Clegg $\mathrm{T}^{2}$, Sheridan $\mathrm{H}^{1}$, Yearsely $\mathrm{D}^{3}$, O’Brien $\mathrm{T}^{3}$, Egan $\mathrm{J}^{3}$ and Mullowney $\mathrm{P}^{1}$ \\ ${ }^{1}$ Department of Agriculture, Fisheries and Food, Kildare Street, Dublin 2, Ireland \\ ${ }^{2}$ Centre for Veterinary Epidemiology and Risk Analysis, UCD Agriculture, Food Science and Veterinary Medicine, \\ University College Dublin, Belfield, Dublin 4, Ireland \\ ${ }^{3}$ Central Veterinary Research Laboratory, Backweston Campus, Young's Cross, Celbridge, Co. Kildare, Ireland
}

\begin{abstract}
A simple random survey was conducted in Ireland during 2005 to estimate the ELISA-prevalence of paratuberculosis, commonly called Johne's disease (JD), in the cattle population. Serum samples were collected from all 20,322 females/breeding bulls over 12 monthsof-age in 639 herds. All samples were tested using a commercially available absorbed ELISA. The overall prevalence of infected herds, based on the presence of at least one ELISA-positive animal, was $21.4 \%$ (95\% Cl 18.4\%-24.9\%). Herd prevalence levels amongst dairy herds (mean 31.5\%; 95\% Cl: 24.6\%, 39.3\%) was higher than among beef herds (mean 17.9\%; 95\% Cl: 14.6\%-21.8\%). However, the animal level prevalence was similar. The true prevalence among all animals tested, was calculated to be $2.86 \%(95 \% \mathrm{Cl}: 2.76,2.97)$ and for animals $>=2 y \mathrm{ys}$, it was $3.30 \%(95 \% \mathrm{Cl}: 3.17,3.43)$. For animals in beef herds, true prevalence was $3.09 \%(95 \% \mathrm{Cl}: 2.93$, 3.24), and for those in dairy herds, $2.74 \%(95 \% \mathrm{Cl}: 2.59,2.90)$. The majority of herds had only one ELISA-positive infected animal. Only $6.4 \%(95 \%$ $\mathrm{Cl} 4.7 \%-8.7 \%)$ of all herds had more than one ELISA-positive infected animal; $13.3 \%$ (Cl 8.7\%-19.7\%) of dairy herds ranging from two to eight ELISA-positive infected animals; and, 3.9\% beef herds ( $\mathrm{Cl} 2.4 \%-6.2 \%)$ ranging from two to five ELISA-positive infected animals. The true prevalence of herds infected and shedding Mycobacterium avium subspecies paratuberculosis is estimated to be $9.5 \%$ for all herd types; $20.6 \%$ for dairy herds; and $7.6 \%$ for beef herds. If ELISA positive animals <2-years-of-age are excluded, the true herd prevalene reduces to: $9.3 \%$ for all herd types; $19.6 \%$ for dairy herds; and $6.3 \%$ for beef herds based on a test specificity (Sp) of $99.8 \%$ and test sensitivity (Se) (i.e., ability to detect culture-positive, infected animals shedding at any level) of $27.8-28.9 \%$.
\end{abstract}

KEYWORDS: herd ELISA-prevalence, Ireland, Johne's disease, Mycobacterium avium subspecies paratuberculosis, Paratuberculosis

\section{CORRESPONDING AUTHOR:}

Margaret Good

Tel: +3531607 2265

Fax: +3531607 2866

E-mail: margaret.good@agriculture.gov.ie

Irish Veterinary Journal volume 62 Number 9 597-606 2009

\section{INTRODUCTION}

Paratuberculosis or Johne's disease (JD) is a chronic infectious granulomatous enteritis of ruminants, which has a worldwide occurrence. It is caused by Mycobacterium avium subspecies paratuberculosis (MAP). There is an agedependent increase in resistance to MAP thus, normally, animals are infected as calves with clinical signs appearing later in life typically between four to six-years-of-age. The disease is characterised by persistent diarrhoea, weight loss and protein losing enteropathy followed by death (Collins 2003a). JD is considered to be one of the most serious diseases affecting dairy cattle (Ott et al. 1999) as there is no effective treatment and disease can cause significant economic loss in affected herds. Losses are associated with reduced milk yield, lower reproductive efficiency, premature culling and decreased cull cow values (Whitlock 1996; Ott et al. 1999; Hendrick et al. 2005; Lombard et al. 2005; Barrett et al. 2006). The relatively long incubation period means that cows may well be culled from the herd for a variety of reasons before the farmer is aware of the presence of JD in the herd (Barrett et al. 2006). In addition, it can be difficult to identify trulyinfected herds given the lack of a consistently reliable diagnostic method. Test sensitivity (Se) improves in herds with higher prevalence of disease. Also, as animals develop 
or approach development of clinical symptoms and in addition, the positive predictive value of an ELISA-positive result is higher as the magnitude of the test result (OD reading) rises (Collins 2003b). It is probable, therefore, that some truly-infected herds had ELISA-negative results either because cows in the later stages of infection had already been culled and/or animals in the early stage of infection were non-responsive and also, that some herds with ELISA-positive results are truly not infected. Nevertheless, for the purposes of this study, an ELISApositive result is taken to indicate an animal infected by MAP which would be faecal culture positive, even if not exhibiting clinically evident disease symptoms.

Estimates of true herd prevalence in European countries varies from $31-71 \%$ in the Netherlands (Muskens et al. 2000), 47\% in Denmark (Nielsen et al. 2000) and 18\% in Belgium (Boelaert et al. 2000). In France, a 2001 study reported by Dufour et al. (2004) quotes a herd ELISAprevalence rate range from $0.02-4.57 \%$ according to the Departement (French administrative subdivision), while Lillini et al. (2005) reported at least $42 \%$ of cattle farms affected by JD in the Latium region of Italy. The herd-level prevalence estimates of JD amongst beef cattle in various regions of the US and Belgium ranges between $7.9 \%$ and 50\% (Turnquist et al. 1991; Collins et al. 1994; Thorne and Hardin 1997; Boelaert et al. 2000; Dargatz et al. 2001). JD has been a scheduled and notifiable disease in Ireland since 1955. The incidence of reported disease was sporadic prior to the mid 1990's, despite the payment of compensation for confirmed cases at the time. Only 92 cases were diagnosed between 1932 and 1992, primarily in imported animals (Department of Agriculture, Fisheries \& Food [DAFF]). Although definitive data are lacking, JD did not appear to be widely established in Ireland during this period. In contrast, it was recognised as an important animal health problem elsewhere in Europe. In 1920, France was the first country to organise control of paratuberculosis by vaccination and, in 1964, Great Britain also permitted voluntary vaccination. In 1922, the Netherlands commenced testing with paratuberculin, avian tuberculin and, from 1931, the Johnin allergy test (Benedictus et al. 2000). The likelihood of JD introduction into Ireland increased in 1992 with the advent of the Single European market, which facilitated the free movement of animals within the EU. Ireland was required to abandon national rules regarding JD including pre-import testing, certification and post-import quarantine. Between 1992 and May 2004, approximately 85,000 cattle were imported from continental Europe. This compares to only 8,383 animals imported between 1979 and 1990. These figures were sourced from the Central Statistics Office, Cork, Ireland, (personal communication) which collects data on the numbers, type and countries of origin of all imported animals. Most imported animals were used for breeding purposes and had come from the Netherlands, Denmark, France and Germany.

Between 1995 and 2002, DAFF received notification of 232 JD affected cattle in 106 herds. Cashman et al. (2008) reported $20 \%$ prevalence in dairy herds in a localised area in the south of Ireland. In 1997, a serological survey, using the absorbed ELISA test, of 224 imported animals in 36 herds, revealed that $36 \%$ of the herds involved had, at least, one ELISA-positive infected animal (O'Doherty et al. 2002).

Concern has been raised of potential links between JD in cattle and Crohn's disease in people with an ongoing scientific debate (McFadden et al. 1987; Ghadiali et al. 2004; Shanahan and O'Mahony 2005). In particular, concerns have been raised about the presence of MAP in raw milk (O'Reilly et al. 2004). If MAP was shown to have zoonotic consequences, this could be very serious for the dairy industry worldwide (Groenendaal and Zagmutt 2008) and also for Ireland, where exports of milk and milk products make a significant contribution to GDP.

The aim of this survey was to provide an estimate of the prevalence and distribution of JD among provinces, herd enterprise types and herds of different sizes within the Republic of Ireland.

\section{MATERIALS AND METHODS Study population}

A list of all bovine breeding herds was obtained from Ireland's Cattle Movement and Monitoring System (CMMS). Since the mid-1950s, DAFF has registered each cattle herd, the epidemiological unit of relevance, with a unique identification herd number. The CMMS contains details of all bovine births from 1996 onwards. Data relating to imports, movements, slaughterings, exports and deaths is complete from the year 2000 onwards.

At the end of December 2003, the bovine population in Ireland was distributed between 123,500 herds. In total, there were $6.5 \mathrm{~m}$ animals on the database: including $3.4 \mathrm{~m}$ females and 300,000 bulls aged 12-months-of-age or over (CMMS 2003).

Breeding herds were defined as those where at least one calf had been registered on CMMS as born in the herd in 2003 (CMMS 2003). A simple random sample of 1,000 herds was taken from the 96,163 herds that met this definition. This sample size is sufficient to estimate a national herd-level prevalence of $10 \%$, with a $95 \%$ confidence interval precision of $+/-2 \%$. Information on the age, sex and breed of cattle in the selected herds was obtained from CMMS. As no date of birth is recorded in CMMS for animals born before 1996, all animals with no recorded date of birth were assumed to be greater than 10-years-of-age.

Herd enterprise type, i.e., dominantly a dairy, beef or mixed herd, was determined using the breed of cows in each herd and the proportion of beef to dairy breeds. The attribution of dairy or beef to a particular breed is as per the designation in Table 1. Herds were classified as dairy if $\geq 66 \%$ of cows in the herd were of a dairy breed. Likewise, herds were classified as beef if $\geq 66 \%$ of cows in the herd were of a beef breed. All other herds were defined as 'mixed'. The value $66 \%$ is that used to determine specialist dairy herds in the national farm survey. 
Table 1: Breeds used to determine enterprise type (dairy, beef or mixed), as recorded in the Irish Cattle Movement Monitoring System (CMMS) database (code, percentage based on Irish cow population in 2005)

\begin{tabular}{|l|l|}
\hline $\begin{array}{l}\text { A dairy breed (48.2\%) is any animal } \\
\text { recorded on the database as one of } \\
\text { the following breeds: }\end{array}$ & $\begin{array}{l}\text { Beef breeds (50.4\%) are any other } \\
\text { breeds the main ones being: }\end{array}$ \\
\hline FR (Friesian/Holstein): 47.1\% & AA (Angus): 6.3\% \\
\hline AY (Ayrshire) & AU (Aubrac) \\
\hline BS (Brown Swiss) & BB (Belgian Blue): $2.6 \%$ \\
\hline RD (Danish Red) & CH (Charolais): $12.1 \%$ \\
\hline GU (Guernsey) & HE (Herford): 7.7 \% \\
\hline JE (Jersey) & LM (Limousin): 12.1 \% \\
\hline KE (Kerry) & SI (Simmental): $7.8 \%$ \\
\hline MO (Montbelliarde): 1.1 \% & SH (Shorthorn): 1.8\% b \\
\hline MY (MRI/MRY) Meuse Rhine (Y) \\
ISSel
\end{tabular}

a Breed percentages are presented for $\mathbf{9 8 . 6 \%}$ of the $\mathbf{2 0 0 5}$ cow population. The shortfall (1.4\%) includes a multiplicity of other breeds without a supplied percentage.

${ }^{b}$ Although some Shorthorn cows may be milked in dairies, in this study, all were regarded as beef animals.

\section{Sample collection}

Under Ireland's Brucellosis eradication programme, each female and bull over 12-months-of-age in all herds, are blood sampled annually. This constitutes a full-herd sampling. During 2005, when a blood sample from a fullherd sampling of one of the 1,000 randomly selected herds was received, a computer programme in the DAFF official Brucellosis testing laboratory notified staff that all samples from the herd were required for a JD ELISA. Samples were stored at the Brucellosis laboratory before being transmitted to the Central Veterinary Research laboratory for testing. All samples so submitted were assayed, including samples from animals over 12-months-of-age and under two-years-of-age at time of sampling.

\section{Serological testing}

Samples were tested using a commercial ELISA test kit for JD, Pourquier ELISA Paratuberculosis Antibody Screening (Institut Pourquier, Montpellier, France). This ELISA measures serum antibodies to MAP and has a reported Se to detect culture positive animals shedding MAP at any level, of 27.8 to $28.9 \%$ and Sp greater than $99.8 \%$ (Collins et al. 2005).

A cut off point of optical density (OD) $>70$, as recommended by the manufacturer, was deemed to indicate a positive response. All other responses were classified negative in the data analysis.

\section{Data analysis}

Two different values for apparent herd-level prevalence were calculated:

1. Case definition A: where a herd was classified as positive if it contained at least one ELISA-positive animal; and,

2. Case definition $B$ (more conservative): calculated by classifying a herd as positive only if it contained more than one ELISA-positive animal.

True prevalence was calculated at both animal and herd level (Martin et al. 1992), assuming a test Sp of $99.8 \%$ and Se of detecting MAP shedding of $27.8 \%$ and $28.9 \%$ (Collins et al. 2005). The test Se and Sp were assumed not to vary by age. Animal level true prevalence was calculated stratified by age. Calculations of the true herd prevalence rely on the estimation of herd Se and $\mathrm{Sp}$, which in turn is a function of the sample size per herd. In this survey, all females and bulls over one-year-old in the herd on the day were sampled. Therefore, the number of animals sampled per herd varied widely. The true herd prevalence was calculated within groups of herds using a weighted average of stratum specific estimates as described by Muskens et al. (2000). The strata were defined based on the quartiles of herd size and the weight per stratum was the number of herds in that stratum divided by the total number of herds. Herd prevalence was calculated at national, provincial (Connaught, Leinster, Munster, Ulster) and enterprise (beef, dairy and mixed) level. In calculating national prevalence, the four groupings were based on herd size: $\leq 11,12-24$, 25-43 and $>43$. Where there were too few positive herds in the smaller herd size groups to provide a reliable estimate, these groups were merged together. For dairy herds, therefore, calculations were determined using three groups based on herd size: $\leq 49,50-74$ and $>74$. For beef herds, two groups based on herd size: $\leq 30$ and $>30$. Similarly, for estimates by province: for Connaught and Ulster, true herd prevalence was calculated for all herds, i.e., there was no grouping by herd size; for Leinster, two groups were based on herd size: $\leq 53$ and >53; and, for Munster, two groups based on herd size: $\leq 51$ and $>51$. A Chi-square test was used to compare the herd prevalence by province and enterprise type. A Wilcoxon rank-sum test (WRS test) was used to compare the median herd-size of positive and negative herds. Confidence intervals for the observed ELISA-prevalence were calculated using exact methods. Because the animals used by Collins (2005) to determine test Se and Sp were >2-years-of-age, the calculation was repeated excluding animals younger than that. In this case, when calculating national prevalence, the four groupings were based on herd size: $\leq 9,10-18.5,18.6-34$ and $>34$. Where there were too few positive herds in the smaller herd size groups to provide a reliable estimate, these groups were merged together. For dairy herds, therefore, calculations were determined using three groups based on herd size $\leq 41,42-56,>56$. For beef herds, there were two groups based on herd size $\leq 24$ and $>24$. Similarly, for estimates by province, for Connaught and Ulster, true herd prevalence was calculated for all herds, i.e., there 
was no grouping by herd size; for Leinster, two groups were based on herd size: $\leq 40.5$ and $>40.5$; and, for Munster, two groups based on herd size: $\leq 41$ and $>41$. An ANOVA test was used to compare OD measurements in positive animals across age groups (ages: $1,2,3 \ldots>10$ ).

\section{RESULTS}

Samples from 639 herds were subjected to JD ELISA. Of these, 458 herds were classified as beef herds (71.7\%), 165 were classified as dairy herds (25.8\%) and the remaining 16 (2.5\%) were classified as mixed herds. The size of herds tested varied widely with tested dairy and mixed herds tending to be bigger than tested beef herds (Table 2).

Table 2: Herd size and number by enterprise type

\begin{tabular}{|l|l|l|l|}
\hline Enterprise type & Number of herds & Herd size range & Median \\
\hline Dairy & 165 & $1-202$ & 49 \\
\hline Beef & 458 & $1-144$ & 18 \\
\hline Mixed & 16 & $10-116$ & 44 \\
\hline Total & 639 & $1-202$ & 24 \\
\hline
\end{tabular}

\section{Herd level prevalence}

Of the 639 herds sampled, 137 herds $(21.4 \%$ [95\% Cl 18.4\%-24.9\%]) had one or more positive animals, $6.4 \%$ had more than one positive animal (Table 3). Table 4 displays both the apparent and true herd level prevalences at national, provincial and enterprise level for both case definitions, including and excluding animals <2-years-of-age. Only seven herds had ELISA-positive animals exclusively $<2$-years-of-age. The number of mixed herds in the sample set was too small to calculate herd prevalence with any degree of precision. The herd level prevalence varied significantly between province $(p<0.001)$ and enterprise type $(p<0.001)$. The prevalence of herds with more than one ELISA-positive animal also varied significantly between provinces $(p=0.024)$ and enterprise type $(p=0.006)$. In beef herds with more than one ELISA-positive animal, $51 \%$ of the positive animals had been introduced into the herd. In dairy herds, the corresponding figure was $14 \%$. Herd size, as determined by the number of animals in the herd eligible for sampling, of ELISA-negative herds (median $=20.5$ animals, QR25 $=10$ animals, QR75 = 35 animals) was significantly smaller $(p<0.001)$ compared to ELISApositive herds (median $=44$ animals, QR25 $=25$ animals, QR75 = 74 animals).

\section{Animal level prevalence}

From the 20,322 individual animal samples, 201 were classified as ELISA-positive for JD. The majority of herds had no ELISA-positive animal, $21.4 \%$ had one or more ELISA-positive animals, and only $6.4 \%$ (95\% Cl 4.7\%-8.7\%) of all herds had more than one ELISA-positive animal. In the dairy herds, $13.3 \%(\mathrm{Cl} 8.7 \%-19.7 \%)$ had between two and eight ELISA-positive animals, and in the beef herds, $3.9 \%$ (ci $2.4 \%-6.2 \%$ ) had between two and five ELISApositive animals.
Table 3: Number of positive animals in herds per enterprise type

\begin{tabular}{|c|c|c|c|c|c|}
\hline Herd size ${ }^{1}$ & $\begin{array}{l}\text { No. of } \\
\text { positive } \\
\text { animals } \\
\text { in herd }\end{array}$ & Beef & Dairy & Mixed & Total \\
\hline \multirow[t]{3}{*}{$<=11$} & 0 & 140 & 13 & 1 & 154 \\
\hline & 1 & 8 & & & 8 \\
\hline & 2 & 1 & & & 1 \\
\hline \multirow{3}{*}{$>11$ and $<=24$} & 0 & 122 & 18 & & 140 \\
\hline & 1 & 21 & 1 & & 22 \\
\hline & 2 & 3 & & & 3 \\
\hline \multirow[t]{4}{*}{$>24$ and $<=43$} & 0 & 90 & 28 & 6 & 124 \\
\hline & 1 & 20 & 3 & 1 & 24 \\
\hline & 2 & 5 & 1 & & 6 \\
\hline & 3 & 2 & 1 & & 3 \\
\hline \multirow[t]{7}{*}{$>43$} & 0 & 24 & 54 & 6 & 84 \\
\hline & 1 & 15 & 26 & 1 & 42 \\
\hline & 2 & 3 & 12 & 1 & 16 \\
\hline & 3 & 2 & 7 & & 9 \\
\hline & 4 & 1 & & & 1 \\
\hline & 5 & 1 & & & 1 \\
\hline & 8 & & 1 & & 1 \\
\hline Total & & 458 & 165 & 16 & 639 \\
\hline
\end{tabular}

${ }^{1}$ Herd-size groups are based on the quartiles of the distribution of herd-sizes.

The majority (75\%) of positive animals were four-years-ofage and over with 30\% classified as over 10-years-of-age (Figure 1). The average OD reading in positive animals was not significantly different (F-test: $p=0.714$ ) across age groups.

The true prevalence among all animals tested was calculated to be $2.86 \%$ (95\% Cl: $2.76-2.97)$, and for animals $\geq 2 y r s$ it was $3.30 \%$ (95\% Cl: 3.17-3.43). Animal prevalence by age are displayed in Table $\mathbf{5}$. For animals in beef herds, true prevalence was 3.09\% (95\% Cl: 2.93$3.24)$, and for those in dairy herds, $2.74 \%(95 \% \mathrm{Cl}: 2.59-$ 2.90).

The average within herd prevalence was $2.8 \%$ (95\% Cl: $2.4 \%-3.2 \%)$ rising to $3.6 \%$ (95\% Cl: 3.0\%-4.4\%) in herds with more than one positive result. The herd with the highest number of positive results had a within-herd animal level ELISA-prevalence of 3.96\% (95\% Cl: 1.8\%-7.9\%).

\section{DISCUSSION}

In the present study, no attempt was made to confirm the presence of JD in herds with one or more ELISA-positive animals or to establish the presence of an alternative reason for sensitisation to MAP antigens. The prevalence of JD detected among herds in this survey is lower than has been reported in many other European countries. A Dutch survey carried out in 1998 estimated that the herd prevalence of paratuberculosis in the Netherlands was $31-71 \%$ and the true prevalence of dairy cattle, 2.7$6.9 \%$ (Muskens et al. 2000). This lower prevalence in 
Table 4: Apparent and True (estimated) herd prevalence of Mycobacterium avium subspecies paratuberculosis infection stratified by region

\begin{tabular}{|c|c|c|c|c|}
\hline & $\begin{array}{l}\text { Case definition A } \\
\text { (1 +ve or more) ELISA- } \\
\text { prevalence \% (95\% Cl) }\end{array}$ & $\begin{array}{l}\text { Case definition B (two or more } \\
+v e) \\
\text { ELISA-prevalence } \% \text { ( } 95 \% \text { Cl) }\end{array}$ & True Prevalence ${ }^{1}$ & Total Number of herds \\
\hline & \multicolumn{4}{|c|}{ Including all animals } \\
\hline National & $21.4(18.4,24.9)$ & $6.4(4.7,8.7)$ & $9.5^{2,3}$ & 639 \\
\hline Connaught & $12 \quad(8.0,18.1)$ & $2(0.6,6.0)$ & $6.2^{2,4}$ & 180 \\
\hline Leinster & $32(24.5,40.4)$ & $9 \quad(5.2,15.6)$ & $14.0^{2,5}$ & 141 \\
\hline Munster & $23 \quad(17.9,28.8)$ & $8 \quad(4.9,12.3)$ & $14.8^{2,6}$ & 240 \\
\hline Ulster & $19(11.5,30.0)$ & $8 \quad(3.1,16.6)$ & $12.8^{2,4}$ & 78 \\
\hline Dairy & $31.5(24.6,39.3)$ & $13.3(8.7,19.7)$ & $20.6^{2,7}$ & 165 \\
\hline \multirow[t]{2}{*}{ Beef } & $17.9(14.6,21.8)$ & $3.9(2.4,6.2)$ & $7.6^{2,8}$ & 458 \\
\hline & \multicolumn{4}{|c|}{ Excluding animals aged $<2$} \\
\hline National & $19.0(16.0,22.3)$ & $5.8(4.2,8.0)$ & $9.3^{2,9}$ & 632 \\
\hline Connaught & $11.1 \quad(7.1,16.8)$ & $1.1(0.1,4.4)$ & $3.4^{2,4}$ & 180 \\
\hline Leinster & $27.1 \quad(20.1,35.4)$ & $7.8 \quad(4.1,14.0)$ & $14.5^{2,10}$ & 140 \\
\hline Munster & $21.4 \quad(16.4,27.3)$ & $7.7 \quad(4.7,12.1)$ & $13.8^{2,11}$ & 234 \\
\hline Ulster & $15.4 \quad(8.5,25.7)$ & $7.7 \quad(3.1,16.6)$ & $12.6^{2,4}$ & 78 \\
\hline Dairy & $30.4(23.6,38.2)$ & $12.4(7.9,18.8)$ & $19.6^{2,12}$ & 161 \\
\hline Beef & $15.2(12.0,18.9)$ & $3.5(2.1,5.8)$ & $6.3^{2,13}$ & 455 \\
\hline
\end{tabular}

1 Based on a test sensitivity of $27.8 \%$ and specificity of $99.8 \%$.

2 Based on herds with two or more ELISA-positive animals.

3 True herd prevalence based on grouping herds into four groups based on herd size $(<=11,12-24,25-43,>43)$.

${ }^{4}$ True herd prevalence calculated for all herds, i.e., there was no grouping by herd size.

${ }^{5}$ True herd prevalence based on grouping herds into two groups based on herd size $(<=53,>53)$.

${ }^{6}$ True herd prevalence based on grouping herds into two groups based on herd size $(<=51,>51)$.

${ }^{7}$ True herd prevalence based on grouping herds into three groups based on herd size $(<=49,50-74,>74)$.

${ }^{8}$ True herd prevalence based on grouping herds into two groups based on herd size $(<=30,>30)$.

${ }^{9}$ True herd prevalence based on grouping herds into four groups based on herd size $(<=9,10-18.5,18.6-34,>34)$.

${ }^{10}$ True herd prevalence based on grouping herds into two groups based on herd size $(<=40.5,>40.5)$

${ }^{11}$ True herd prevalence based on grouping herds into two groups based on herd size $(<=41,>41)$.

${ }^{12}$ True herd prevalence based on grouping herds into three groups based on herd size $(<=41,42-56,>56)$.

${ }^{13}$ True herd prevalence based on grouping herds into two groups based on herd size $(<=24,>24)$.

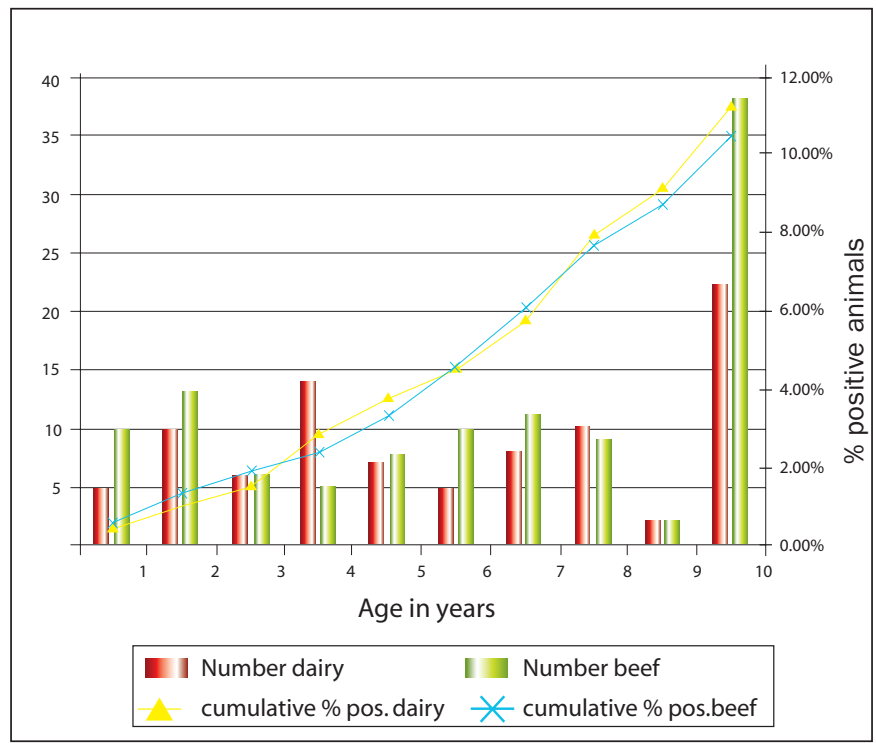

Figure 1: Number and percentage of ELISA-positive animals by age in dairy and beef herds.
Table 5: Apparent and true (estimated) animal prevalence of Mycobacterium avium subspecies paratuberculosis infection stratified by age

\begin{tabular}{|l|l|l|l|}
\hline Age & $\begin{array}{l}\text { Apparent } \\
\text { seroprevalence } \\
\%(95 \% \text { Cl) }\end{array}$ & $\begin{array}{l}\text { True prevalence } \\
\%(95 \% \text { Cl) }\end{array}$ & $\begin{array}{l}\text { Total number of } \\
\text { animals }\end{array}$ \\
\hline$<2$ & $0.59(0.40,0.86)$ & $1.41(1.24,1.58)$ & 4764 \\
\hline 2 & $0.64(0.39,1.02)$ & $1.59(1.36,1.82)$ & 2833 \\
\hline 3 & $0.56(0.30,1.00)$ & $1.30(1.06,1.55)$ & 2151 \\
\hline 4 & $1.04(0.64,1.66)$ & $3.04(2.68,3.41)$ & 1819 \\
\hline $5+$ & $1.42(1.18,1.69)$ & $4.42(4.23,4.62)$ & 8755 \\
\hline$>=2$ & $1.11(0.95,1.29)$ & $3.30(3.17,3.43)$ & 15,558 \\
\hline Total & $0.99(0.86,1.14)$ & $2.86(2.76,2.97)$ & 20,322 \\
\hline
\end{tabular}

${ }^{1}$ Based on a test sensitivity of $27.8 \%$ and specificity of $99.8 \%$. 
Ireland, may merely be a consequence of the relatively late introduction and establishment of JD as a disease entity following the abolition of the pre-import checks and post-import quarantine as a consequence of the Single Market within the EU in 1992. There is a general belief that the prevalence of JD has been increasing in Ireland over the last decade. This was also reported by Drier et al. (2006) who observed an increase in serum antibodies against MAP in Austria following the introduction of the single market. If this is the case, prevalence will likely continue to rise to match prevalence elsewhere, unless appropriate preventive and corrective action is taken. The lower prevalence in Ireland may also be influenced by the Bovine Tuberculosis Eradication programme ongoing in Ireland since 1954. There is some evidence that herds in Ireland with JD are also liable to be infected with $M$. bovis or at least produce reactors to the TB test (Mullowney et al. 2008). There is some evidence to indicate that exposure to $M$. avium induces low-level protection against $M$. bovis, but compromises disease diagnosis (Hope et al. 2005). The same may be true of exposure to MAP i.e., a natural vaccination effect, since many antigens are shared in common between M. bovis and MAP (Leroy et al. 2009; Santema et al. 2009), but the diagnosis of both conditions simultaneously in the same animals (Aranaz et al. 2006) would seem to indicate that there is little, if any, effective cross immunity conferred by infection with either. Natural infection with MAP, as well as the use of MAP vaccines (not currently legally allowed in Ireland), have been demonstrated to compromise the specificity of diagnostic tests for tuberculosis (Alvarez et al. 2009; Aranaz et al. 2006; Lilenbaum et al. 2009). The reverse is also true where tuberculosis (Alvarez et al. 2009; Lilenbaum et al. 2009) and the intradermal tuberculin test (Varges et al. 2009) interferes with the diagnosis of infection with MAP. Balseiro et al. (2003) reported that false positive responses to the tuberculin test (single intradermal test) as a consequence of other mycobacterial infection, particularly MAP, is of concern in Spain and, citing an article in Spanish by Juste et al. (2000), claims that this accounts for approximately $30.4 \%$ of positive TB test reactors in cattle. Animals that produce a positive response to the TB test are compulsorily slaughtered under the eradication programme. Since both MAP and M. bovis belong to the same genus, it is possible that animals susceptible to MAP and even perhaps infected by MAP are being removed from the Irish bovine population as an unexpected consequence of the Bovine Tuberculosis Eradication programme. Ongoing studies attempting to identify genetic resistance in bovines may also provide support for this opinion if genetic susceptibility factors common to both diseases are identified (Koets et al. 2000; Gonda et al. 2006; Settles et al. 2009; Bermingham et al. 2009). This premise would merit further research in areas where both diseases are common. In this context, it is interesting to note that countries, at least in Europe, with the highest reported prevalence of JD, appear to be now free from bovine TB (Reviriego Gordejo and Vermeersch 2006). The results of the survey indicate that the prevalence of
ELISA-positivity in dairy herds is higher than in beef herds. This is particularly worrying given the concerns associated with MAP in milk and fears of a zoonotic implication. The higher ELISA-positivity observed in dairy herds provides evidence to support a hypothesis that the opening of the European market increased the incidence of JD in Ireland. The majority of animals imported from continental countries after 1992 were dairy animals imported by farmers in Ireland in an attempt to improve the productivity of their dairy herds. Nielsen et al. (2008) determined that in Denmark, calves fed colostrums from multiple cows had an odds ratio of 1.24 of being ELISA-positive, compared with calves fed colostrums from their own dam only. Calves sucking with foster cows had an odds ratio of 2.01 of being ELISA-positive, compared with calves being fed milk replacer. The increased ELISA-positivity in dairy herds may also have resulted from the common practice in Ireland for dairy herd managers to feed pooled colostrum and waste milk to calves regardless of their future breeding potential (Cashman et al. 2008). Feeding pooled colostrum is cited as contraindicated for JD control in many national disease control programmes (McKenna et al. 2006) and also on JD advice websites such as www.johnes.org Pooling colostrum and milk means that one infected cow excreting MAP can infect multiple calves. The nature of beef farming, where ordinarily calves are suckled on their own dam, does not facilitate within-herd MAP transmission in this particular manner, although some cross-suckling may occur. However, in some pedigree beef herds in Ireland, it is relatively common to source additional supplemental milk supplies from dairy herds, and, thus, calves in such herds are exposed to the same risk of MAP transmission as calves in a dairy herd.

It is also interesting to note that a higher percentage of ELISA-positive animals in beef herds involved bought-in animals, when compared with dairy herds. Many beef herd owners choose to source half-bred beef heifers from dairy herds as replacement suckler dams, so as to exploit their relatively higher milk yield and calf rearing potential. As the prevalence of JD in dairy herds rises, so too does the risk of acquiring a MAPinfected half-bred heifer from a dairy herd. The common use of natural service for suckler dams also means that breeding bulls require replacement at regular intervals in beef herds. The pedigree sector is the one sub-sector of the beef industry that would also have imported a significant number of pedigree breeding animals from continental countries after 1992. Thus, pedigree beef bulls are also a particular risk. This finding re-enforces the need for herd owners to take special care when sourcing animals, particularly for expanding herds.

Dairy herds and, to a lesser extent, beef herds expanded in size generally in Ireland in recent decades and expansion is a particular risk for disease introduction.

The 1998 survey in the Netherlands showed that on $70 \%$ of the positive farms, only one or two animals were ELISApositive for MAP (Muskens et al. 2000). In this survey, we had $70 \%$ of 'infected' farms with just one ELISA-positive animal. This rises to $89 \%$ if farms with only two ELISA- 
positive animals are included. The Sp of the MAP ELISA (99.8\% or $2 / 1,000$ samples) is such that false positive test results can be expected and, indeed, at this level some $40-41$ of the 20,322 samples assayed for this survey could be false positive. Thus, since the positive predictive value of the assay increases as the number of positive animals in the herd increases (Collins, 2003b), it is quite likely that many of the herds with only one ELISApositive animal may not actually be infected with MAP. Indeed, it is unlikely that the unexpectedly high number of ELISA-positive animals under three-years-of-age, 38 or $19 \%$ of the total, (Figure 1) were responding positively due to MAP infection given the pathobiology of JD and the higher Se and positive predictive value of the ELISA as an animal approaches onset of clinical symptoms. Most MAP-infected animals do not show a high antibody response before the terminal stages of the disease (Collins, 2003b; Nielsen et al. 2002a) and animals under three-years-of-age are less likely (two to three times less) than older, higher parity animals to be positive (Nielsen et al. 2002b). In this study, we found animals aged three years or less to have a lower estimated prevalence (Table 5). We also compared OD measurements across the age groups to evaluate if the ELISA-positive animals in the group aged three years or less showed lower titres than older animals, but there was no statistical difference. The probability of false positives created problems in classifying ELISA-positive herds as infected herds, particularly as so many had only one single ELISA-positive test result. Therefore it was decided to calculate the true herd prevalence using herds with more than one positive result.

In keeping with the pathobiology of JD, however, as animals aged, the percentage showing ELISA-positive also rose

(Figure 1). The rapid rise in the percentage showing ELISApositive was particularly noticeable in dairy herds when cows were four-years-of-age. The rate of increase in the percentage of beef cows showing ELISA-positive was much more gradual and didn't commence until age five. It is likely that cows in dairy herds are under more stress than cows in beef herds and, hence, the propensity to sero-convert at a younger age. The higher absolute number of beef cows, ELISA-positive, over 10-years-of-age reflects the fact that there are more old beef cows than old dairy cows in this survey (Figure 1), as there is in the general Irish cattle population (Maher et al. 2008).

The variation in prevalence between the different provinces reflects the different enterprise types dominant in those provinces. The gradation of prevalence levels from Munster (13.8-14.8\%), through Leinster (14.5-14.0\%), Ulster (12.6$12.8 \%)$ and Connaught (3.4-6.2\%), excluding or including animals <2-years-of-age respectively, is indicative of the predominance of intensive dairy farming in Munster compared to Connaught, where small, extensive sucklerbeef farms predominate. Small suckler-beef farms of the type predominating in Connaught were also much less likely to have imported animals from continental Europe. Although the initial target was to sample 1,000 herds, logistical problems meant that samples were tested from only 639 of the randomly selected herds. The proportions of herds in the beef, dairy and mixed enterprise categories in these 639 herds closely mirrors the national distribution of such enterprises in 2003 of $71.9 \%, 25.3 \%$ and $2.8 \%$ respectively as determined using the same methodology (CMMS 2003). Richardson et al. (2009) also used the herds from this survey to determine that the herds in this survey were representative of the population and distribution of breeding herds at the national, provincial and enterprise levels. They used both the original selection of 1,000 herds and the 639 herds that constituted the final sample, as well as a further opportunistic sample (non-probability sampling) to demonstrate the use of non-GIS methods, such as the proportion of herds within each enterprise type as detailed above, and GIS methods comparing the spatial distribution of herds within the survey to other randomly selected samples, nearest neighbour analysis and kernel density plots. Therefore, the herds used within this analysis are likely to provide a reliable estimate of disease prevalence in the target population.

One problem in conducting serological surveys for JD is the reliability of ELISA tests in determining infection levels. In the case of JD, animals usually become infected as calves and develop clinical disease as adults several years later (Chiodini et al. 1984). Antibodies to MAP do not appear until late in the incubation period making ELISA tests unsuitable for the detection of infected animals early in the incubation period (Collins 1996; Collins 2003b). Se estimates are highly variable reflecting the type of animal sampled and where the animal was positioned in the disease cycle. Ridge et al. (1991) estimated the Se of the ELISA test to be $88.3 \%$ in clinical cases, $48.8 \%$ in subclinical cases, and $59.7 \%$ in animals concurrently shedding MAP at time of sampling. Jubb et al. (2004), when estimating the Se of the ELISA used in low prevalence dairy herds during the Victorian JD test and control programme, showed differing sensitivities in animals in different age groups being lower in two to four-year-old animals and higher in older age groups with $13.5 \%$ the lowest estimate of Se. Sweeney et al. (1995) showed that the Se in low-level fecal shedders could be as low as $15 \%$. In 2005 , van Schaik et al. reported that field validation of the Pourquier ELISA in Dutch dairy cows demonstrated it to be highly specific (99.3\%) and fairly sensitive $(51.3 \%)$ relative to faecal culture.

$\mathrm{Sp}$ of the ELISA test is generally much better. Estimates from a putative JD 'free' area in Australia put the Sp of the ELISA test at 99.8\% (Ridge et al. 1991) and, overall, the Sp of absorbed ELISAs are considered to be greater than 99\% (Collins, 1996). Sp estimates, however, are likely to vary somewhat between different regions because of inherent differences in the microflora prevalent in the area (Collins et al. 2005; Nielsen et al. 2002a). False-positive serum ELISA results have been reported (Osterstock et al. 2007), as caused by environmental mycobacteria. Environmental mycobacteria are abundant in the Irish environment and 
known to cause non-specific sensitisation to tuberculins (Cooney et al. 1997). Leroy et al. (2009) further report that if $M$. bovis exposed cattle are used as a negative control, $\mathrm{Sp}$ of the MAP Pourquier test was only $91.6 \%$, i.e., four sera among 48 were detected as false-positive. Although $M$. bovis is quite prevalent in the Irish environment, the $M$. bovis status of the ELISA-positive herds or animals were not determined in this study.

Despite the increased reporting of clinical cases of JD in recent years, disease prevalence in Ireland is still relatively low. Many farmers are not aware of the disease or the production difficulties it can cause and, thus, it is difficult to convince them of the serious threat it poses. Moreover, they are unlikely to make management changes or adopt the necessary on-farm biosecurity practices, with the commitment and persistence vital to either exclude entry of JD to the farm or limit within herd spread unless aware of the issues and the status of his or her herd. Thus, publicity and an education campaign for JD are necessary in Ireland. There are quite sufficient economic costs and animal welfare issues due to JD on affected farms, to make on-farm control or prevention of this disease desirable. However, current testing methods for JD are not satisfactory at individual animal level and, thus, the need to develop herds, with low risk of, or freedom from, MAP infection from which to source replacement breeding stock. This is particularly advisable for the cohort of high genetic merit dairy herds and herds producing beef breeding bulls. There is no national control plan for JD in Ireland at the time of writing, although recently, a partnership between industry and government has been formed under the title Herd Health Ireland to address a number of non-regulated conditions and diseases including JD. It is vital that the industry make informed decisions in respect of JD, as if a link between it and Crohn's Disease is ever established, countries with programmes in place are likely to have a distinct competitive advantage.

It would be advisable to repeat this survey at intervals to monitor changes in prevalence, bearing in mind that stratification of the sampling frame prior to sample selection would facilitate the production of more precise results for the different enterprise types in each province. Also, as the problems with test Se can make it difficult to accurately determine the status of a herd containing only one or two breeding cows, the reliability of the results could be improved by restricting sampling to herds with more than 10 calves registered per year.

\section{ACKNOWLEDGEMENTS}

The authors wish to acknowledge the assistance of all who contributed to this paper and, in particular, the DAFF staff involved in the Animal Health Computer System who helped compile the data. We also wish to acknowledge Peter Maher of DAFF and Esther Richardson of Teagasc who organised various computer programmes and systems and input test results respectively; laboratory staff, Seamus Power, Helen Tracey and Frances Foran at the Brucellosis laboratory in Cork; and, finally, Darren Hand and Niamh
Connolly at CVRL who assisted in the collation and analysis of samples.

\section{REFERENCES}

Alvarez J, de Juan L, Bezos J et al. (2009) Effect of paratuberculosis on the diagnosis of bovine tuberculosis in a cattle herd with a mixed infection using interferon-gamma detection assay. Vet Microbiol 135(3), 389-393.

Aranaz A, de Juan L, Bezos J et al. (2006) Assessment of diagnostic tools for eradication of bovine tuberculosis in cattle co-infected with Mycobacterium bovis and $M$. avium subsp. paratuberculosis. Vet Res 37(4) 593-606.

Balseiro AM, Prieto J, Espí Perez V et al. (2003) Presence of focal and multifocal paratuberculoisis lesions in mesenteric lymph nodes and the the ileocaecal valve of cattle positive to the tuberculin skin test. The Veterinary Journal 166, 210-212.

Barrett DJ, Good M, Hayes M et al. (2006) The economic impact of Johne's disease in an Irish dairy herd: A case study. Irish Vet J 59(5), 282-288.

Benedictus G, Verhoeff J, Schukken YH et al. (2000) Dutch paratuberculosis programme history, principles and development. Vet Microbiol 77, 399- 413.

Bermingham ML, More SJ, Good M et al. (2009) Genetics of tuberculosis in Irish Holstein-friesian dairy herds. J Dairy Sci (in press).

Boelaert F, Walravens K, Biront P et al. (2000) Prevalence of paratuberculosis (Johne's disease) in the Belgian cattle population Vet Microbiol 77, 269-281.

Cashman W, Buckley J, Quigley T et al. (2008) Risk factors for the introduction and within-herd transmission of spread of Mycobacterium avium subsp. paratuberculosis (MAP) infection on 59 Irish dairy herds. Irish Vet J 61(7), 464-467.

Chiodini RJ, Van Kruiningen HJ, Merkal RS (1984) Ruminant paratuberculosis (Johne's disease): the current status and future prospects. Cornell Vet. 74, 218-262.

CMMS statistics report 2003. National Beef Assurance Division. The Department of Agriculture and Food, Dublin, Ireland.

Collins MT (1996) Diagnosis of paratuberculosis. Vet. Clin. North Am.: Food Anim. Practice 12(2), 357-371.

Collins MT (2003a) Update on paratuberculosis: 1. Epidemiology of Johne's disease and the biology of Mycobacterium paratubertulosis. Irish Vet J 56, 565574.

Collins MT (2003b) Update on paratuberculosis: 2. Pathology and diagnosis. Irish Vet J 56, 619-623.

Collins MT, Sockett DC, Goodger WJ et al. (1994) Herd prevalence and geographic distribution of, and risk factors for, bovine paratuberculosis in Wisconsin. J Am Vet Med Assoc 204(4), 636-641.

Collins MT, Wells SJ, Petrini KR et al. (2005) Evaluation of five antibody detection tests for diagnosis of bovine paratuberculosis. Clin Diag Lab Immun 12(6), 685692.

Cooney R, Kazda J, Quinn, Muller K et al. (1997) 
Environmental mycobacteria in Ireland as a source of non-specific sensitisation to tuberculins. Irish Vet J 50, 370-373.

Dargatz DA, Byrum BA, Hennager SG BarBer, LK et al. (2001) Prevalence of antibodies against Mycobacterium avium subsp. paratuberculosis among beef cow-calf herds. J Am Vet Med Assoc 219, 497-501.

Drier S, Khol JL, Stein B et al. (2006) Serological, bacteriological and molecularbiological survey of paratuberculosis (Johnes's disease) in Austrian cattle. J Vet Med B Infect Dis Vet. Public Health. 53(10), 477-81.

Dufour B, Pouillot R and Durand B (2004) A cost/benefit study of paratuberculosis certification in French cattle herds. Vet Res 35(1), 69-81.

Ghadiali AH, Strother M, Naser SA et al. (2004) Mycobacterium avium subsp. paratuberculosis strains isolated from Crohn's disease patients and animal species exhibit similar polymorphic locus patterns. J Clin Microbiol 42(11), 5345.

Gonda MG, Chang YM, Shook GE et al. (2006) Genetic variation of Mycobacterium avium ssp paratuberculosis infection in US Holsteins. J Dairy Sci 89, 1804-1812.

Groenendaal H, Zagmutt FJ (2008) Scenario analysis of changes in consumption of dairy products caused by a hypothetical causal link between Mycobacterium avium subspecies paratuberculosis and Crohn's disease. J Dairy Sci 91, 3245-3258.

Hendrick SH, Kelton DR, Leslie KE et al. (2005) Effect of paratuberculosis on culling, milk production, and milk quality in dairy herds. J Am Vet Med Assoc 227(8), 1302-1308.

Hope JC, Thom ML and Villarreal-Ramos B (2005) Exposure to Mycobacterium avium induces low-level protection from Mycobacterium bovis infection but compromises diagnosis of disease in cattle. Clin Exp Immunol 141, 432-439.

Jubb TF, Sergeant ESG, Callinan APL et al. (2004). Estimate of the Se of an ELISA used to detect Johne's disease in Victorian dairy cattle herds. Aust Vet J 82, 569-573.

Koets AP, Adugna G, Janss LLG et al. (2000) Genetic variation of susceptibility to Mycobacterium avium subsp. paratuberculosis infection in dairy cattle. J Dairy Sci 83, 2702-2708.

Leroy B, Viart S, Trinchero N et al. (2009) Use of Mycobacterium avium subsp. paratuberculosis specific coding sequences for serodiagnosis of bovine paratuberculosis. Vet Microbiol 135(3-4), 313-9.

Lilenbaum W, Marassi CD, Varges R et al. (2009) Occurrence of false-positive results in three Partuberculosis-ELISAs performed in a tuberculous herd. Vet Res Commun (in press).

Lillini E, Biotonti G, Gamberale F et al. (2005) Prevalence of bovine paratuberculosis in the Latium region (Italy). Proceedings 8th International Colloquium on Paratuberculosis August 14-18, 2005 Copenhagen, Denmark.

Lombard JE, Garry FB, McCluskey BJ et al. (2005) Risk of removal and effects on milk production associated with paratuberculosis status in dairy cows. J Am Vet Med Assoc 227, 1975-1981.

Maher P, Good M and More SJ (2008) Trends in cow numbers and culling rate in the Irish cattle population, 2003 to 2006. Irish Vet J 61(7), 455-463.

Martin SW, Shoukri M and Thorburn MA (1992) Evaluating the health status of herds based on tests applied to individuals. Prev Vet Med 14, 33-43.

McFadden JJ, Butcher PD, Chiodini R et al. (1987) Crohn's disease-isolated mycobacteria are identical to Mycobacterium paratuberculosis, as determined by DNA probes that distinguish between mycobacterial species. J. Clin Microbiol 25, 796-801.

McKenna SLB, Keefe GP, Tiwari A et al. (2006) Johne's disease in Canada Part II: Disease impacts, risk factors, and control programs for dairy producers. Can Vet J 47(11), 1089-1099.

Mullowney P, Good M, Costello E et al. (2008) The effect of infection with Mycobacterium avium Subsp. paratuberculosis on tuberculin testing in suckler herds in Ireland. Proceedings XXV Jubilee World Buiatrics Congress, Budapest Hungary July 6-11, 2008.

Muskens J, Barkema HW, Russchen E et al. (2000) Prevalence and regional distribution of paratuberculosis in dairy herds in the Netherlands. Vet Microbiol 77, 253-261.

Nielsen SS, Thamsborg SM, Houe H et al. (2000) Bulk-tank milk ELISA antibodies for estimating the prevalence of paratuberculosis in Danish dairy herds. Prev Vet Med 44, 1-7.

Nielsen SS, Thamsborg SM, Houe H et al. (2000) Corrigendum to "bulk-tank milk ELISA antibodies for estimating the prevalence of paratuberculosis in Danish dairy herds'. Prev Vet Med 46, 297.

Nielsen SS, Grønbaek C, Agger JF et al. (2002a) Maximumlikelihood estimation of Se and Sp of ELISAs and faecal culture for diagnosis of paratuberculosis. Prev Vet Med 53, 191-204.

Nielsen SS, Enevoldsen C, Gröhn YT (2002b) The Mycobacterium avium subsp. paratuberculosis ELISA response by parity and stage of lactation. Prev Vet Med 54, 1-10.

Nielsen SS, Bjerre H, Toft N (2008) Colostrum and milk as risk factors for infection with Mycobacterium avium subsp. paratuberculosis in dairy cattle. J Dairy Sci 91, 4610-4615.

O'Doherty A, O'Grady D, O'Farrell K et al. (2002) Survey of Johnes' disease in imported cattle in the Republic of Ireland. Vet Rec 150, 634-636.

O'Reilly CE, O'Connor L, Anderson W et al. (2004) Surveillance of bulk raw and commercially pasteurised cows' milk from approved Irish liquid-milk pasteurisation plants to determine the incidence of Mycobacterium paratuberculosis. Appl Environ Microbiol 70, 5138-5144.

Osterstock JB, Fosgate GT, Norby B Manning et al. (2007) Contribution of environmental mycobacteria to false- 
positive serum ELISA results for paratuberculosis. J Am Vet Med Assoc 230(6), 896-901.

Ott SL, Wells SJ, Wagner BA (1999) Herd level economic losses associated with Johne's disease in US dairy operations. Prev Vet Med 40, 179-192.

Reviriego Gordejo FJ and Vermeersch JP (2006) Towards eradication of bovine tuberculosis in the European Union. Vet Microbiol 112, 101-109.

Richardson E, Good M, McGrath G et al. (2009) The use of Geographic Information System (GIS) and non-GIS methods to assess the external validity of samples post-collection. J Vet Diagn Invest, Vol. 21, Number 5, September 2009 (in press).

Ridge SE, Morgan IR, Sockett DC et al. (1991) Comparison of the Johne's absorbed EIA and the complement fixation test for the diagnosis of Johne's disease in cattle. Aust Vet J 68, 253-257.

Santema W, Overdijk M, Barends J et al. (2009) Searching for proteins of Mycobacterium avium subspecies paratuberculosis with diagnostic potential by comparative qualitative proteomic analysis of mycobacterial tuberculins. Vet Microbiol doi:10.1016/j. vetmic.2009.03.021

Settles M, Zanella R, McKay SD et al. (2009) A whole genome association analysis identifies loci associated with Mycobacterium avium subsp. paratuberculosis infection status in US Holstein cattle. Anim Genet (in press).

Shanahan F, O'Mahony J (2005) The mycobacteria story in Crohn's disease. Am J Gastroenterol 100(7), 15371538.

Sweeney RW, Whitlock RH, Buckley CL et al. (1995) Evaluation of a commercial enzyme-linked immunosorbent assay for the diagnosis of paratuberculosis in dairy cattle. J Vet Diagn Invest $7(4)$, 488-493.

Thorne JG, Hardin LE (1997) Estimated prevalence of paratuberculosis in Missouri, USA cattle. Prev Vet Med 31(12), 51-57.

Turnquist SE, Snider TG, Kreeger GM et al. (1991)

Serological evidence of paratuberculosis in Louisiana beef cattle herds as detected by ELISA. Prev Vet Med 11(2), 125-130.

van Schaik G, Stehman SM, Jacobson RH et al. (2005) Cow-level evaluation of a kinetics ELISA with multiple cutoff values to detect fecal shedding of Mycobacterium avium subspecies paratuberculosis in New York State dairy cows. Prev Vet Med 72(3-4), 22136.

Varges R, Marassi CD, Oelemann W et al. (2009) Interference of intradermal tuberculin tests on the serodiagnosis of paratuberculosis in cattle. Res Vet Sc 86, 371-372.

Whitlock R (1996) Johne's Disease. In: Smith BP (Ed.): Large Animal Internal Medicine, 899-904. $2^{\text {nd }}$ Ed., Mosby, St Louis, Missouri; 1996. 